\title{
Correction to: Heterologous production of chlortetracycline in an industrial grade Streptomyces rimosus host
}

\author{
Xuefeng Wang ${ }^{1,2} \cdot$ Shouliang Yin ${ }^{3}$. Jing Bai ${ }^{1} \cdot$ Yang Liu $^{3} \cdot$ Keqiang Fan ${ }^{4} \cdot$ Huizhuan Wang ${ }^{2} \cdot$ Fang Yuan $^{2}$. \\ Baohua Zhao ${ }^{1} \cdot{\text { Zilong } \mathrm{Li}^{4} \text { (D) Weishan Wang }}^{4}$
}

Published online: 14 January 2020

(C) Springer-Verlag GmbH Germany, part of Springer Nature 2020

\section{Correction to: Appl Microbiol Biotechnol (2019) https://doi.org/10.1007/s00253-019-09970-1}

The original version of this article contains error.

When organizing the panels of Fig. $5 \mathrm{c}$, we repeatedly copied the data of the resistance levels of SRC4, i.e., mistakenly copied the data of the $25 \mu \mathrm{g} / \mathrm{mL}$ CTC resistance level of SRC4 as the $0 \mu \mathrm{g} / \mathrm{mL}$ resistance level of SRC3. We would like to correct it in the below figure.

We sincerely apologize for this error.

Xuefeng Wang and Shouliang Yin contributed equally to this work.

The online version of the original article can be found at https://doi.org/ 10.1007/s00253-019-09970-1

\footnotetext{
Baohua Zhao

zhaobaohua@hebtu.edu.cn

Zilong Li

lizl@im.ac.cn

$\bowtie$ Weishan Wang

wangws@im.ac.cn

1 College of Life Science, Hebei Normal University, Shijiazhuang 050024, Hebei, People's Republic of China

2 Hebei Shengxue Dacheng Pharmaceutical Co., Ltd., Shijiazhuang 051430, Hebei, People's Republic of China

3 School of Life Sciences, North China University of Science and Technology, Tangshan 063210, Hebei, People's Republic of China

4 State Key Laboratory of Microbial Resources, Institute of Microbiology, Chinese Academy of Sciences, Chaoyang District, Beijing 100101, People's Republic of China
} 
C

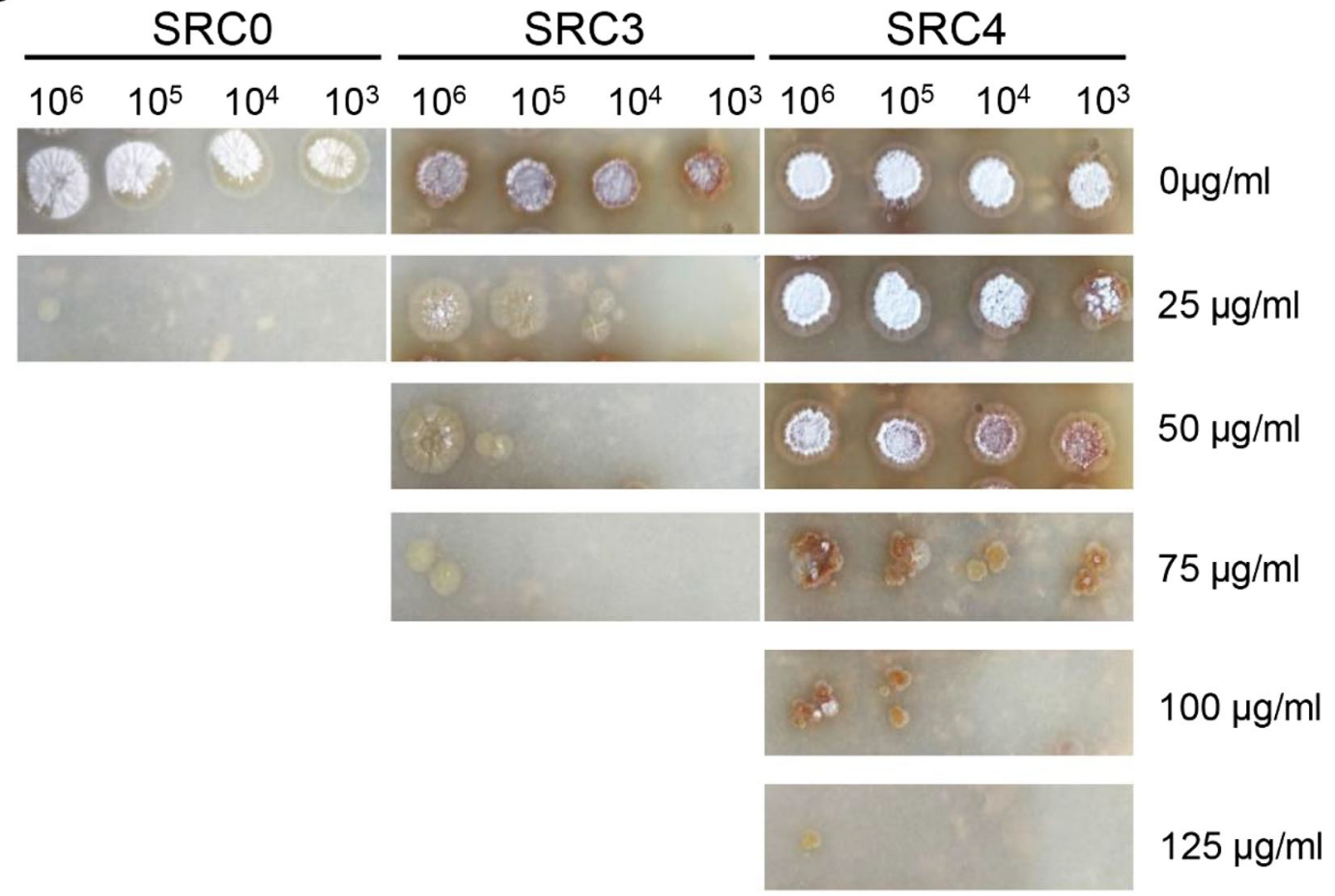

Publisher's Note Springer Nature remains neutral with regard to jurisdictional claims in published maps and institutional affiliations. 